\title{
A Prospective 30-Year Follow-Up of ADHD Associated With Perinatal Risks
}

\section{Tervo, Timo}

2017

Tervo , T , Michelsson, K , Launes , J \& Hokkanen , L 2017 , ' A Prospective 30-Year

Follow-Up of ADHD Associated With Perinatal Risks ' , Journal of Attention Disorders, vol. 21 , no. 10 , pp. $799-810$. https://doi.org/10.1177/1087054714548036

http://hdl.handle.net/10138/237200

https://doi.org/10.1177/1087054714548036

publishedVersion

Downloaded from Helda, University of Helsinki institutional repository.

This is an electronic reprint of the original article.

This reprint may differ from the original in pagination and typographic detail.

Please cite the original version. 


\title{
A Prospective 30-Year Follow-Up of ADHD Associated With Perinatal Risks
}

Journal of Attention Disorders

2017, Vol. 21(10) 799-810

(C) The Author(s) 2014

Reprints and permissions:

sagepub.com/journalsPermissions.nav

DOI: 10.1 I77//0870547/4548036

journals.sagepub.com/home/jad

(S)SAGE

\author{
Timo Tervo', Katarina Michelsson', Jyrki Launes², and Laura Hokkanen²
}

\begin{abstract}
Objective: Longitudinal follow-up of ADHD suggests a poorer outcome in those affected. Studies extending to 30 years however are rare. We investigated the adult outcome of ADHD associated with perinatal risks (PRs), treated non-pharmacologically. Method: A study group of 122 participants ( 86 men, 36 women) with PR-associated ADHD was followed-up from birth and compared with a control group also prospectively studied. Results: The study group showed more cognitive, motor perception, and learning impairments as well as psychiatric problems at ages 5 , 9, and I6. At age 30, the study group reported less education, more involuntary job dismissals and more alcohol abuse. Self-reported ADHD symptoms were still prevalent in adulthood. Conclusion: ADHD symptoms persist and impair the long-term educational, occupational, and psychiatric outcome. ADHD in participants with PR appears to follow a course seen in studies of unselected ADHD. (J. of Att. Dis. 20I 7; 2 I(I0) 799-8I0)
\end{abstract}

\section{Keywords \\ ADD/ADHD, cognitive development, psychosocial outcome, longitudinal study}

\section{Introduction}

The worldwide prevalence of ADHD in childhood and adolescence is estimated at 5\% (Polanczyk, de Lima, Horta, Biederman, \& Rohde, 2007). Follow-up studies on children with ADHD have suggested that the disorder persists in adulthood in approximately two thirds of cases. Approximately $15 \%$ retain symptoms to fulfill diagnostic criteria, and another 50\% have a partial remission (Barkley, Fischer, Smallish, \& Fletcher, 2002; Biederman, Mick, \& Faraone, 2000; Faraone, Biederman, \& Mick, 2006). Though the severity of the symptoms is reduced compared with childhood, approximately $75 \%$ to $90 \%$ of adult ADHD participants have at least some functional deficit (Biederman, Petty, Clarke, Lomedico, \& Faraone, 2011). Childhood ADHD symptom severity, the presence of a combined subtype, and other comorbidities such as conduct, and mood or anxiety disorders, psychosocial adversity, and parental psychopathology contribute to adult ADHD (Biederman et al., 2011; Lara et al., 2009). Longitudinal studies are needed to clarify their complex interactions. To the best of our knowledge there are only three prospective follow-up studies of ADHD that extend to the age of 30 (Biederman et al., 2012; Klein et al., 2012; Satterfield et al., 2007). However, these include only men and recruited participants were referred to specialty clinics at the age of 6 or more.

The cause of ADHD is thought to be an interaction of multiple genetic and environmental risk and protective factors (Nigg, 2006; Thapar, O'Donovan, \& Owen, 2005;
Willcutt et al., 2010). The incidence of ADHD is higher in participants with pre- and perinatal risks (PRs; Gustafsson \& Källén, 2011; Halmøy, Klungsøyr, Skjærven, \& Haavik, 2012; Sagiv, Epstein, Bellinger, \& Korrick, 2013) as compared with the general population. The relationship is not fully established and the effect of low birth weight, post term pregnancy, low Apgar scores, or fetal distress could not be confirmed in a recent study (Silva, Colvin, Hagemann, $\&$ Bower, 2013). The heritability of ADHD has been estimated at $60 \%$ to $80 \%$ when both genetic main effects and gene and environment interaction effects are included, whereas that of environmental effects alone is around $20 \%$ to $40 \%$ (Kooij et al., 2010; Nigg, 2006). Based on such heterogeneity, it seems plausible to hypothesize that the spectrum of the ADHD syndrome has extremes in which the course and the long-term outcome are variably affected by different number of biological and environmental effects. Most studies however include participants with heterogeneous origin of symptoms.

We present here 30-year follow-up results of 122 male and female participants who all have ADHD associated with PRs. The aim is to compare the long-term cognitive,

\footnotetext{
'Helsinki University Hospital, Finland

${ }^{2}$ University of Helsinki, Finland

Corresponding Author:

Laura Hokkanen, Institute of Behavioural Sciences, University of Helsinki, P.O. Box 9, 000 I4 HY, Helsinki, Finland.

Email: laura.hokkanen@helsinki.fi
} 
social, occupational, and psychiatric outcome of this ADHD group with those of controls, similarly followed-up.

\section{Material and Method}

\section{The Participants}

The study group belongs to a cohort prospectively followed up since 1971. Childhood findings have been published earlier (Lindahl \& Michelsson, 1987; Michelsson \& Lindahl, 1987; Michelsson, Ylinen, \& Donner, 1981; Michelsson, Ylinen, Saarnivaara, \& Donner, 1978). A new project "Plasticity" pre-protocol based on the same cohort is published elsewhere (Hokkanen, Launes, \& Michelsson, 2013). Briefly, newborns with PR factors were consecutively selected at a primary care maternity hospital in Helsinki, Finland between January 1st 1971 and December 31st 1974. During this period, 22,359 infants were born alive at the hospital. These births accounted for approximately $10 \%$ of the births in Finland and about half of the births in Helsinki metropolitan area. The study cohort $(n=1,196)$ comprised of new-born infants with any of the following PRs: low birth weight $(\leq 2,000 \mathrm{~g})$, neurological symptoms, severe respiratory problems, Apgar score $<7$ at 5 or $15 \mathrm{~min}$ of age, hyperbilirubinemia, hypoglycaemia, septic infections, and a maternal diabetes (Michelsson et al., 1978). Twenty percent of the newborns in the cohort had more than one risk factor concomitantly. Mortality was $12 \%$ during the first month, $2 \%$ of the cohort died before the age of 5 years. Four percent were severely disabled and were excluded from the study. Of the remaining 994 persons, 865 (87\%) were included in follow-up. Forty-five percent were girls, 55\% boys.

The control group initially comprised of 169 children (50\% boys and $50 \%$ girls). They were born at the same maternity hospital but had none of the PRs. The children lived in the same metropolitan area and attended the same or similar public schools as the risk cohort. Fifty-eight were followed from birth, and 111 from the age of 9 years, recruited from normal classes from the same schools as the study cohort.

Ethical review has been conducted over the course of the longitudinal study, and the latest approval was obtained from the Ethical Review Board of the Helsinki and Uusimaa hospital district in May 2013 (number 147/13/3/00/2013).

\section{Method and the Diagnosis of ADHD}

The diagnostic evaluation for the present study was performed using the Diagnostic and Statistical Manual of Mental Disorders (4th ed.; DSM-IV, American Psychiatric Association [APA], 1994) criteria. Data were obtained from the prospectively collected database which includes repeated clinical examinations, structured developmental tests, a review of the hospital records, as well as ratings by parents and teachers. Table 1 gives the details of clinical evaluations performed at 5, 9, 16, and 30 years of age.

At the age of 5, during 1976 to 1979 , each child was evaluated in a clinical case conference with a pediatrician (K.M.), a child neurologist, a psychologist, and a speech therapist present. The neurologist, the psychologist, and the speech therapist each gave their independent evaluation on the child's behavior regarding hyperactivity and inattention as a part of the study protocol. Those with problems were referred to a child neurological and psychiatric unit for further multidisciplinary diagnostic evaluation. Neurodevelopmental impairments including either "hyperkinetic reaction of childhood" as defined in the DSM-II (2nd ed.; APA, 1968), or "minimal brain dysfunction" (MBD; Clements, 1966; Hagberg, 1975), were diagnosed. MBD was defined in this study to include (a) motor impairments, (b) perceptual and learning difficulties, (c) speech and language problems, and (d) psychiatric/behavioral problems including hyperactivity. All problems were recorded, and MBD was diagnosed if the child had impairments in at least three of these areas. The multidisciplinary assessment was repeated when the children were 9 years of age.

In 2010, the case files of those diagnosed with hyperactivity, attentional deficit, or MBD at the age of 5 or 9 were re-evaluated by an investigator (K.M.) who had initially met the children, to ensure that the onset and persistence of the hyperactivity/impulsivity or inattention symptoms were as defined in the DSM-IV (APA, 1994) ADHD criteria. The onset before 7 years of age and the persistence of symptoms beyond 6 months were verified by comparing the data from 5 and 9 years of age, and the presence of symptoms in different settings was verified by comparing the data gathered from parents, teachers, and the clinical visits. Symptoms of inattention, hyperactivity, and impulsivity were included in the structured evaluations given by the teachers, parents, and researchers.

The socioeconomic status of the family was estimated using 5 levels, 1 indicating the highest and 5 the lowest level, based on the occupation of the father (or mother, in cases of a single caretaker). Data from 5, 9, and 16 year assessments was pooled and the highest obtained socioeconomic level was used in the analyses.

\section{Questionnaire at Age 30}

In 2003 to 2004, a questionnaire was sent to the study cohort and control participants who had previously taken part in the study. The questionnaire included long-term outcome variables, and the following domains with total of 35 items are reported here: school performance (remedial education used, persisting learning difficulties, writing difficulties, reading difficulties, perceptual problems, mathematical problems, speech problems, motor/dexterity problems), 
Table I. Assessment Methods Used at Different Age Periods.

\begin{tabular}{|c|c|}
\hline \multirow[t]{7}{*}{5 years } & Clinical history and examination \\
\hline & Neurodevelopmental examination (Bax \& Whitmore, 1983; Michelsson, Ylinen, \& Donner, I98I) \\
\hline & Illinois Test of Psycholinguistic abilities (ITPA; Kuusinen \& Blåfield, I974) \\
\hline & Dubowitz Cognitive screening test (Dubowitz, Leibowitz, \& Goldberg, 1977) \\
\hline & Draw-a-person test (Goodenough, 1926) \\
\hline & Parents' and day care personnel's structured evaluation of child's behavior \\
\hline & $\begin{array}{l}\text { Family psychosocial problems score: poor housing conditions, divorces, several relocations, alcohol } \\
\text { abuse, unemployment, family conflicts, domestic violence, imprisonment, severe diseases or mental } \\
\text { problems in family, summed, max score } 50\end{array}$ \\
\hline \multirow[t]{9}{*}{9 years } & Clinical history and examination \\
\hline & ITPA (Kuusinen \& Blåfield, I974) \\
\hline & Test of Motor Impairment (TOMI; Stott, Moyes, \& Henderson, 1972) \\
\hline & Wechsler Intelligence Scale for Children (WISC; Wechsler, I97I) \\
\hline & $\begin{array}{l}\text { Reading and spelling tests standardized for Finnish children, ranging from } 4 \text { (failure) to } 10 \text { (excellent; } \\
\text { Ruoppila, Röman, \& Västi, 1968, 1969) }\end{array}$ \\
\hline & Parents' structured evaluation of child's behavior and school performance \\
\hline & $\begin{array}{l}\text { Teacher's rating of school achievement in reading, writing, mathematics, gymnastics, handicraft, and visual } \\
\text { arts, each graded } 0 \text { (good performance), I (mediocre performance), or } 2 \text { (poor performance), summed }\end{array}$ \\
\hline & $\begin{array}{l}\text { Teacher's structured evaluation of problem behavior ( } 25 \text { questions scored from I to } 5 \text {, summed, higher } \\
\text { scores indicate more undesirable behavior) }\end{array}$ \\
\hline & Family psychosocial problems score, see above \\
\hline \multirow[t]{2}{*}{16 years } & Questionnaire on school performance (self-report) \\
\hline & Youth Rating Scale (Achenbach \& Eldebrock, 1987) \\
\hline \multirow[t]{2}{*}{30 years } & Questionnaire on educational, occupational, psychiatric, and health outcomes (self-report) \\
\hline & ADHD Childhood and Current Symptom Scales (Barkley \& Murphy, 1998) \\
\hline
\end{tabular}

educational and occupational achievement (graduation from high school, highest degree completed, the type of present employment, number of past jobs, involuntary dismissals due to own conduct), general health (subjective health, use of prescribed sedatives or hypnotics, past concussions, doctor's appointments), psychiatric symptoms (depression, anxiety, panic attacks, compulsive symptoms, manic-depression, temper management issues, sleep problems, suicidal thoughts, general life satisfaction, depressive mood), social well-being (living conditions, satisfaction with social contacts, need for social support) substance use (illicit drugs, alcohol, tobacco, intoxicated driving). The questionnaire also included the ADHD Current Symptoms Scale as well as the ADHD Childhood Symptoms Scale by Barkley and Murphy (1998) where each of the 18 DSM-IV diagnostic criteria symptom are scored from 0 to 3 , depending on the severity of symptoms.

\section{Statistical Analysis}

Variable means in the text are accompanied with standard deviations $(S D)$ in parenthesis. The comparisons were performed in a stratified manner for each age period. We conducted univariate analyses because of missing data. To avoid the type I error caused by multiple testing, the Bonferroni correction was applied to the desired $p=.05$ level. The number of outcome variable comparisons at the age of 5 was 4 (the required significance level therefore .0125 ), at the age of 9 it was 7 (the required level .0071), at the age of 16 it was 13 (the required level .0038), and at the age of 30 it was 39 (the required level .0013). Comparisons were performed either using ANCOVA or $t$ test with separate variance estimates for unequal N's. Non-continuous parameters were tested using the Pearson Chi-square test and Fisher's exact test for $2 \times 2$ contingency tables. Relative risks (RR) for the study group obtaining a score in the controls' lowest quartile (or above median in some variables) were calculated using the Mantel-Haenszel paradigm. Calculations were performed using the Statistica 12 statistical software (StatSoft Inc., 2013)

\section{Results}

In the cohort with PRs, 122 children (14\% of the 865 who participated in the follow-up at 5 years), including 86 boys and 36 girls, had ADHD in childhood. Table 2 shows the PRs of these participants. One child in the control group was diagnosed with ADHD.

Five participants with confirmed ADHD symptoms were excluded from the statistical analyses as potential outliers: one with a left hemisphere anomaly, one with Noonan's syndrome, one with Prader-Willi syndrome, one with sequelae of encephalitis, and one with schizophrenia diagnosed at age 22. Three of the children with ADHD were 
Table 2. Perinatal Risks of the Participants With ADHD $(N=122)$.

\begin{tabular}{|c|c|c|c|c|}
\hline \multirow[b]{2}{*}{ Perinatal risk } & \multicolumn{2}{|c|}{ Cases with the risk as a single cause } & \multicolumn{2}{|c|}{ Cases with the risk } \\
\hline & $n$ & $\%$ & $n$ & $\%$ \\
\hline Hyperbilirubinemia & 27 & 22.1 & 38 & 31.1 \\
\hline Apgar score $<7$ & 23 & 18.9 & 40 & 32.8 \\
\hline LBW & 13 & 10.7 & 34 & 27.9 \\
\hline Neurological signs & 9 & 7.4 & $\mathrm{II}$ & 9.0 \\
\hline Maternal diabetes & 6 & 4.9 & 8 & 6.6 \\
\hline Respiratory disorder & 3 & 2.5 & 9 & 7.4 \\
\hline Hypoglycemia & 4 & 4.9 & 15 & 12.3 \\
\hline Several risks & 37 & 30.3 & & \\
\hline Total & 122 & & & \\
\hline
\end{tabular}

Note. Approximately $70 \%$ had a single risk factor causing the inclusion, $30 \%$ had several concomitant risks at birth. LBW $=$ low birth weight $(<2,000 \mathrm{~g})$.

Table 3. Characteristics of the Participants With PR-Associated ADHD and Control Participants at Birth.

\begin{tabular}{|c|c|c|c|c|c|c|c|}
\hline & \multicolumn{2}{|c|}{ PR-associated ADHD } & \multicolumn{2}{|c|}{ Controls } & \multirow{2}{*}{$\begin{array}{l}\text { Difference of } \\
\text { means } 95 \% \mathrm{CL}\end{array}$} & \multirow[b]{2}{*}{$t$} & \multirow[b]{2}{*}{$p$} \\
\hline & $n$ & $M \pm S D$ & $n$ & $M \pm S D$ & & & \\
\hline $\begin{array}{l}\text { Maternal age, } \\
\text { years }\end{array}$ & 117 & $24.7 \pm 4.7$ & 56 & $26.9 \pm 4.5$ & {$[0.7,3.7]$} & -2.9 & .0044 \\
\hline $\begin{array}{l}\text { Birth weight, } \\
\text { grams }\end{array}$ & 117 & $2814 \pm 915$ & 95 & $3419 \pm 528$ & {$[396,813]$} & -5.7 & .0000 \\
\hline Birth height, cm & 117 & $47.6 \pm 3.9$ & 95 & $50.0 \pm 2.1$ & {$[1.6,3.3]$} & -5.5 & .0000 \\
\hline $\begin{array}{l}\text { Head } \\
\text { circumference, } \\
\mathrm{cm}\end{array}$ & 117 & $33.2 \pm 2.8$ & 95 & $34.7 \pm 1.2$ & {$[0.9,2.1]$} & -5.0 & .0000 \\
\hline $\begin{array}{l}\text { Weeks of } \\
\text { gestation }\end{array}$ & 117 & $38 \pm 3.4$ & 95 & $39.6 \pm 1.3$ & {$[1.3,2.8]$} & -5.5 & .0000 \\
\hline Apgar at I min & 117 & $6.6 \pm 2.6$ & 95 & $9.0 \pm 0.7$ & {$[1.9,3.0]$} & -9.1 & .0000 \\
\hline Apgar at $5 \mathrm{~min}$ & 117 & $8.0 \pm 2.5$ & 95 & $9.5 \pm 0.5$ & {$[1.0,2.0]$} & -5.7 & .0000 \\
\hline
\end{tabular}

Note. $\mathrm{PR}=$ perinatal risks; $95 \% \mathrm{CL}=95 \%$ confidence limits, low- and high-end values.

also diagnosed with fetal alcohol syndrome but were not excluded from the analyses. The number of participants in the study group was therefore 177 . The family socioeconomic status, defined as the occupational level of the father, was lower in the study group $(M=2.3, S D=0.9)$ compared with the control group $(1.9, S D=0.8, t=-3.50, p<.001)$. Details on the pregnancies, deliveries, and the new-born period are given in Table 3 .

\section{Results at 5 Years}

Motor and cognitive abilities. Significantly poorer mean scores were found in the group with PR-associated ADHD in all tests measuring neurodevelopmental maturity, verbal and nonverbal linguistic skills, drawing ability, and the early cognition compared with the controls (Table 4). Socioeconomic status was included as a covariant in the analyses. Relative risks indicated almost a threefold risk for those in the study group of scoring in the controls' lowest quartile in early cognitive and psycholinguistic tests.

Social situation. Twenty percent of the mothers of the study group children were the only caretaker as compared with $5 \%$ in the control families $(p<.001)$. The Family psychosocial problems score was 4.3 (3.0) in the study group and 2.4 (2.4) in the control group $(t=3.61, p<.001)$ indicating significantly more problems in families with a child with PR-associated ADHD.

\section{Results at 9 Years}

Motor and cognitive abilities. At the age of 9 years, impairment was found in the group with PR-associated ADHD in motor abilities, verbal and nonverbal linguistic skills, and in intelligence compared with the controls (Table 4). Socioeconomic status was included as a covariant in the analyses. The highest calculated RRs indicated a sixfold risk for those in the study group of scoring in the controls' lowest quartile 
Table 4. Performance in Cognitive Tests at 5 and 9 Years of Age in the PR-Associated ADHD and the Control Groups, and the RR for Score in the Controls' Lowest Quartile for the ADHD Group.

\begin{tabular}{|c|c|c|c|c|c|c|c|c|c|}
\hline & \multicolumn{2}{|c|}{$\begin{array}{l}\text { PR-associated } \\
\text { ADHD }\end{array}$} & \multicolumn{2}{|c|}{ Controls } & \multirow{2}{*}{$\begin{array}{l}\text { Difference } \\
\text { of means } \\
95 \% \mathrm{CL}\end{array}$} & \multirow[b]{2}{*}{$F$} & \multirow[b]{2}{*}{$p^{*}$} & \multicolumn{2}{|c|}{ Relative risk } \\
\hline & $N$ & $M \pm S D$ & $n$ & $M \pm S D$ & & & & $\mathrm{RR}$ & $95 \% \mathrm{CL}$ \\
\hline \multicolumn{10}{|l|}{ At 5 years of age } \\
\hline ITPA total score & III & $32.8 \pm 4.0$ & 38 & $37.1 \pm 2.8$ & {$[2.9,5.6]$} & 30.7 & .0000 & 2.6 & {$[1.6,5.0]$} \\
\hline Draw-a-person test & 83 & $104.8 \pm 29.3$ & 38 & $138.2 \pm 28.1$ & {$[22.1,44.6]$} & 33.2 & .0000 & 0.9 & {$[0.9,1.0]$} \\
\hline $\begin{array}{l}\text { Dubowitz cognitive } \\
\text { screening score }\end{array}$ & 52 & $28.2 \pm 10.5$ & 35 & $40.2 \pm 6.3$ & {$[8.1,15.9]$} & 29.3 & .0000 & 2.9 & {$[1.7,5.5]$} \\
\hline $\begin{array}{l}\text { Neurodevelopmental } \\
\text { examination }\end{array}$ & 116 & $27.4 \pm 16.2$ & 39 & $9.8 \pm 6.0$ & {$[12.4,22.9]$} & 39.2 & .0000 & 1.4 & {$[1.3,1.5]$} \\
\hline \multicolumn{10}{|l|}{ At 9 years of age } \\
\hline ITPA total score & 107 & $33.8 \pm 3.6$ & 91 & $36.8 \pm 3.1$ & {$[2.1,4.0]$} & 32.3 & .0000 & 2.6 & {$[1.8,4.0]$} \\
\hline WISC FSIQ & 82 & $106.1 \pm 15.1$ & 65 & $121.8 \pm 11.8$ & {$[11.2,20.2]$} & 44.3 & .0000 & 2.1 & {$[1.4,3.3]$} \\
\hline Reading test & 46 & $7.7 \pm 1.7$ & 75 & $8.5 \pm 1.3$ & {$[0.2,1.3]$} & 45.0 & .0000 & I.I & {$[1.0,1.2]$} \\
\hline Spelling test & 71 & $6.4 \pm 2.0$ & 82 & $8.2 \pm 1.3$ & {$[1.5,2.4]$} & 4.7 & .0324 & 1.4 & {$[1.2,1.5]$} \\
\hline TOMI score & 109 & $9.3 \pm 5.6$ & 93 & $3.9 \pm 2.8$ & {$[4.1,6.7]$} & 68.2 & .0000 & 6.2 & {$[2.6,16.1]$} \\
\hline
\end{tabular}

Note. PR = perinatal risks; RR = relative risk; $95 \% \mathrm{CL}=95 \%$ confidence limits, low- and high-end values; ITPA = Illinois Test of Psycholinguistic Abilities; WISC = Wechsler Intelligence Test for Children; FSIQ = Full Scale Intelligence Quotient; TOMI = Test of Motor Impairment.

*p value required after Bonferroni's correction at age 5 is .0125 and at age 9 is .0071 .

in the Test of Motor Impairment.

Educational achievement. The school entrance was postponed by 1 year in $6 \%$ of the children with PR-associated ADHD. The teacher rating, indicating underachievement, was 12.5 (2.2) in the study group and 10.5 (2.6) in the control group, $F(1,174)=22.6, p<.0001$, at the second year of school. There was more problem behavior in school as evaluated by the teacher, with the participants with PRassociated ADHD evaluated as more hyperactive, intruding, careless, untrustworthy, irritable, slow, and non-independent, than in the control group. The mean School behavior score was $50.0(15.1)$ in the study group and 31.7 (15.4) in the control group, $F(1,173)=52.6, p<.0001$.

Social situation. Twenty-nine percent of the mothers of study group children were single parents, divorced, widows, or their child had been placed in foster care, whereas the frequency was $7 \%$ in the control families $(p<.001)$. Also, the family psychosocial problems score indicated more problems in the group with PR-associated ADHD (4.6, $S D=$ $3.3)$ than in the control group $(3.2, S D=2.4 ; t=3.17, p<$ $.002)$.

\section{Results at 16 Years}

Educational achievement. By the age of 16 years, 3 children with PR-associated ADHD had not graduated from the primary-level school (first obligatory 9 years) whereas all in the control group had done so. Thirty-one percent of the children in the study group had remedial instruction and
$23 \%$ had been required to repeat a class ( $2 \%$ in controls). The mean of all school grades was $7.1(0.8)$ in the study group and $8.4(0.9)$ in the control group, $F=56.1(1,149)$, $p<.0001$.

Psychiatric problems. The Youth Self-Report revealed more psychiatric problems in the boys in the study group than in the controls (Table 5). Especially externalizing problems were more prevalent. No significant differences (after correcting for multiple comparisons) were detected among girls. Social competence scores of participants with PRassociated ADHD did not differ from the controls.

\section{Results at 30 Years}

Eighty-four participants with PR-associated ADHD returned the questionnaire, but information was available of $93(76 \%$ or the original 122$)$. Nine had died, all men. The immediate cause of death was cardiac in two cases, traffic accident in five, and alcohol or substance abuse in two. Suicide was confirmed in three cases. Of the control participants, 94 (56\% of the original 169) returned the questionnaire.

ADHD symptoms. The study group scored higher than the control group both in the ADHD Childhood Symptom scale and in the Current Symptoms scale (Table 6). Childhood socioeconomic status was included as a covariant in the analyses. Based on the retrospective self-rating of criteria symptoms, 10 participants in the study group were identified as having had the combined type, 4 the 
Table 5. YRS at 16 Years of Age, $T$-Scores $M$ and SD, as Well as $t$ Test for the Differences Between the Ms of the Two Groups.

\begin{tabular}{|c|c|c|c|c|c|c|c|}
\hline & \multicolumn{2}{|c|}{ PR-associated ADHD } & \multicolumn{2}{|c|}{ Controls } & \multirow[b]{2}{*}{$t$} & \multirow{2}{*}{$\begin{array}{l}\text { Difference of } \\
\text { Ms } 95 \% \mathrm{CL}\end{array}$} & \multirow[b]{2}{*}{$p^{*}$} \\
\hline & $n$ & $M \pm S D$ & $n$ & $M \pm S D$ & & & \\
\hline \multicolumn{8}{|l|}{ Boys } \\
\hline Activities scale & 48 & $42.4 \pm 8.1$ & 32 & $45.6 \pm 9.1$ & -1.6 & {$[-7.1,0.7]$} & .1032 \\
\hline Social scale & 48 & $43.0 \pm 9.4$ & 32 & $45.7 \pm 7.2$ & -1.4 & {$[-6.7,1.2]$} & .1644 \\
\hline Total competence score & 29 & $42.9 \pm 8.5$ & 29 & $47.2 \pm 9.8$ & -1.8 & {$[-9.1,0.6]$} & .0815 \\
\hline Depressed & 48 & $57.1 \pm 5.3$ & 32 & $55.3 \pm 1.2$ & 1.8 & {$[-0.2,3.6]$} & .0710 \\
\hline Unpopular & 48 & $57.1 \pm 4.3$ & 32 & $55.0 \pm 0.2$ & 2.7 & {$[0.5,3.6]$} & .0090 \\
\hline Somatic complaints & 48 & $56.1 \pm 2.8$ & 32 & $55.6 \pm 2.1$ & 0.9 & {$[-0.6,1.7]$} & .3612 \\
\hline Self-destructive & 48 & $57.5 \pm 4.6$ & 31 & $55.9 \pm 2.4$ & 1.8 & {$[-0.2,3.4]$} & .0815 \\
\hline Thought disorder & 48 & $57.0 \pm 4.0$ & 32 & $55.9 \pm 2.3$ & 1.4 & {$[-0.4,2.7]$} & .1612 \\
\hline Delinquent & 48 & $57.6 \pm 4.6$ & 32 & $55.3 \pm 1.1$ & 2.7 & {$[0.6,3.9]$} & .0080 \\
\hline Aggressive & 48 & $57.1 \pm 4.8$ & 32 & $55.3 \pm 1.4$ & 2.0 & {$[0.0,3.5]$} & .0474 \\
\hline Total score & 48 & $49.3 \pm 8.7$ & 32 & $43.8 \pm 6.6$ & 3.0 & {$[1.8,9.0]$} & .0037 \\
\hline Internalizing & 48 & $50.5 \pm 9.5$ & 32 & $46.9 \pm 5.8$ & 1.9 & {$[-0.1,7.3]$} & .0568 \\
\hline Externalizing & 48 & $51.9 \pm 8.2$ & 32 & $46.0 \pm 7.9$ & 3.2 & {$[2.3,9.6]$} & .0019 \\
\hline \multicolumn{8}{|l|}{ Girls } \\
\hline Activities scale & 19 & $46.6 \pm 11.1$ & 47 & $50.8 \pm 6.1$ & -2.0 & {$[-8.4,0.0]$} & .0515 \\
\hline Social scale & 19 & $42.8 \pm 10.4$ & 47 & $46.4 \pm 8.4$ & -1.5 & {$[-8.5,1.3]$} & .1493 \\
\hline Total competence score & 15 & $45.1 \pm 11.8$ & 44 & $50.5 \pm 8.3$ & -1.9 & {$[-\mid 1.0,0.1]$} & .0563 \\
\hline Depressed & 19 & $57.2 \pm 4.7$ & 47 & $56.1 \pm 3.4$ & 1.0 & {$[-1.0,3.1]$} & .3083 \\
\hline Unpopular & 19 & $57.1 \pm 3.3$ & 47 & $55.7 \pm 3.0$ & 1.7 & {$[-0.3,3.1]$} & .0972 \\
\hline Somatic complaints & 19 & $57.8 \pm 5.1$ & 47 & $56.8 \pm 5.5$ & 0.7 & {$[-1.9,4.0]$} & .4881 \\
\hline Thought disorder & 19 & $56.6 \pm 3.2$ & 47 & $56.3 \pm 4.1$ & 0.3 & {$[-1.7,2.5]$} & .7363 \\
\hline Delinquent & 19 & $59.6 \pm 7.3$ & 47 & $56.6 \pm 3.2$ & 2.4 & {$[0.5,5.6]$} & .0218 \\
\hline Aggressive & 19 & $58.1 \pm 7.5$ & 47 & $56.6 \pm 3.3$ & 1.2 & {$[-1.1,4.2]$} & .2509 \\
\hline Total score & 19 & $51.2 \pm 10.5$ & 47 & $46.1 \pm 9.7$ & 1.9 & {$[-0.3,10.5]$} & .0648 \\
\hline Internalizing & 19 & $49.8 \pm 10.8$ & 47 & $45.6 \pm 10.4$ & 1.5 & {$[-1.5,9.9]$} & .1483 \\
\hline Externalizing & 19 & $54.6 \pm 9.9$ & 47 & $49.8 \pm 8.5$ & 2.0 & {$[-0.1,9.6]$} & .0524 \\
\hline
\end{tabular}

Note. YRS = Youth Rating Scale; PR = perinatal risk; $95 \% \mathrm{CL}=95 \%$ confidence limits, low- and high-end values.

* $p$ value required after Bonferroni's correction is .0038 , those below are bolded.

Table 6. ADHD Symptom Scores at 30 Years of Age in the PR-Associated ADHD and Control Groups and the RR for Score Above the Control Group Median in the ADHD Group.

\begin{tabular}{|c|c|c|c|c|c|c|c|c|c|}
\hline & \multicolumn{2}{|c|}{$\begin{array}{c}\text { PR-associated } \\
\text { ADHD }\end{array}$} & \multicolumn{2}{|c|}{ Controls } & \multirow{2}{*}{$\begin{array}{l}\text { Difference of } \\
\text { Ms, } 95 \% \mathrm{CL}\end{array}$} & \multirow[b]{2}{*}{$F$} & \multirow[b]{2}{*}{$p^{*}$} & \multicolumn{2}{|c|}{ Relative risk } \\
\hline & $n$ & $M \pm S D$ & $n$ & $M \pm S D$ & & & & $\mathrm{RR}$ & $95 \% \mathrm{CL}$ \\
\hline $\begin{array}{l}\text { Current inattention } \\
\text { symptoms }\end{array}$ & 76 & $4.7 \pm 4.9$ & 94 & $2.3 \pm 2.6$ & {$[1.3,3.6]$} & 16.7 & .0000 & 1.4 & {$[0.9,2.0]$} \\
\hline $\begin{array}{l}\text { Current hyperactive- } \\
\text { impulsive symptoms }\end{array}$ & 76 & $5.4 \pm 4.2$ & 94 & $2.5 \pm 2.6$ & {$[1.9,4.0]$} & 31.8 & .0000 & 2.2 & {$[1.4,3.6]$} \\
\hline $\begin{array}{l}\text { Childhood inattention } \\
\text { symptoms }\end{array}$ & 74 & $9.4 \pm 6.3$ & 93 & $2.7 \pm 3.7$ & {$[5.2,8.3]$} & 68.9 & .0000 & 2.1 & {$[1.7,2.6]$} \\
\hline $\begin{array}{l}\text { Childhood hyperactive- } \\
\text { impulsive symptoms }\end{array}$ & 74 & $9.2 \pm 6.4$ & 93 & $2.4 \pm 3.6$ & {$[5.3,8.3]$} & 71.3 & .0000 & 3.1 & {$[1.8,5.6]$} \\
\hline
\end{tabular}

Note. $\mathrm{PR}=$ perinatal risks; $\mathrm{RR}=$ relative risk; $95 \% \mathrm{CL}=95 \%$ confidence limits, low- and high-end values.

*p value required after Bonferroni's correction is .0013 .

inattention type, and 9 the hyperactive/impulsive type of ADHD in childhood. In adulthood, 1 participant had the symptoms of the combined type, 4 of the inattention type, and none of the hyperactive/impulsive type of ADHD. In the control group, 1 participant was identified as having had the combined type in childhood and the hyperactive/ 
Table 7. Questionnaire Items at 30 Years of Age and the Relative Risks (RR) for Score in the Controls' Lowest Quartile for the PR-Associated ADHD Group.

\begin{tabular}{|c|c|c|c|}
\hline & $\begin{array}{c}\text { Fisher's exact } \\
\text { test } p^{*}\end{array}$ & $\mathrm{RR}$ & $95 \% \mathrm{CL}$ \\
\hline \multicolumn{4}{|l|}{ Cognitive difficulties } \\
\hline Remedial teaching & .0001 & 10.74 & {$[2.58,44.77]$} \\
\hline Subjective writing problem & .0001 & 11.13 & {$[2.67,46.48]$} \\
\hline Subjective learning problems & .0002 & 16.08 & {$[2.15,120.16]$} \\
\hline Subjective mathematical problems & .0004 & 5.26 & {$[1.85,14.97]$} \\
\hline Subjective reading problems & .0007 & 6.18 & {$[1.86,20.58]$} \\
\hline Subjective motor/dexterity problems & .0013 & 9.89 & {$[1.27,77.38]$} \\
\hline Subjective perceptual problems & .0034 & 11.13 & {$[1.44,85.93]$} \\
\hline Subjective speech problems & .0073 & 9.89 & {$[1.27,77.38]$} \\
\hline \multicolumn{4}{|l|}{ Social well-being } \\
\hline Subjective need of social support & .0028 & 4.95 & {$[2.29,10.70]$} \\
\hline Living with spouse & .0040 & 1.84 & {$[1.20,2.83]$} \\
\hline Satisfaction with social contacts/friendship & .0129 & 2.32 & {$[1.15,4.69]$} \\
\hline \multicolumn{4}{|l|}{ Academic achievement and employment } \\
\hline High school graduate & .0000 & 2.88 & {$[2.03,4.07]$} \\
\hline Highest completed degree & .0000 & 3.26 & {$[2.01,5.28]$} \\
\hline Involuntary dismissal from work & .0003 & 8.53 & {$[2.00,36.38]$} \\
\hline Number of past jobs & .0009 & 1.35 & {$[0.98,1.88]$} \\
\hline Current gainful employment & .0021 & 2.77 & {$[1.40,5.46]$} \\
\hline \multicolumn{4}{|l|}{ Health } \\
\hline Subjective over-all health & .0012 & 5.00 & {$[1.98,12.64]$} \\
\hline Hypnotics use & .0797 & 1.89 & {$[0.87,4.14]$} \\
\hline Sedatives use & .0915 & 0.95 & {$[0.89,1.01]$} \\
\hline Past concussions & .0038 & 2.09 & {$[1.29,3.37]$} \\
\hline Number of doctor's appointments last year & .5000 & 1.43 & {$[0.84,2.44]$} \\
\hline \multicolumn{4}{|l|}{ Psychiatric symptoms } \\
\hline Dissatisfaction & .0000 & 2.48 & {$[1.5 \mathrm{I}, 4.07]$} \\
\hline Temper management problems & .0000 & 5.02 & {$[2.17,11.62]$} \\
\hline Anxiety & .0003 & 4.67 & {$[2.00,10.89]$} \\
\hline Depression & .0021 & 2.48 & {$[1.04,5.88]$} \\
\hline Panic attacks & .0034 & 6.70 & {$[1.53,29.33]$} \\
\hline Compulsive symptoms & .0075 & 3.65 & {$[0.39,34.43]$} \\
\hline Sleep problems & .0172 & 6.10 & {$[0.73,51.15]$} \\
\hline Suicidal ideation & .0173 & 6.09 & {$[0.73,51.04]$} \\
\hline Manic-depressive ideation & .3284 & 3.65 & {$[0.39,34.43]$} \\
\hline Depressive mood & .0294 & 3.04 & {$[1.42,6.53]$} \\
\hline \multicolumn{4}{|l|}{ Illicit drugs, alcohol, and smoking } \\
\hline Driving intoxicated & $.000 \mathrm{I}$ & 3.81 & {$[1.82,7.96]$} \\
\hline Use of illicit drugs & .0090 & 2.22 & {$[1.21,4.07]$} \\
\hline Alcohol consumption & .0979 & 6.01 & {$[1.36,26.64]$} \\
\hline Smoking & .1478 & 1.60 & {$[1.05,2.44]$} \\
\hline
\end{tabular}

Note. $\mathrm{PR}=$ perinatal risks; $95 \% \mathrm{CL}=95 \%$ confidence limits, low- and high-end values.

$* p$ value required after Bonferroni's correction is .0013 , those below are bolded.

impulsive type in adulthood. Another control participant reported six or more criteria symptoms of inattention in childhood.

Learning disabilities. At the age of $30,49 \%$ of the participants with PR-associated ADHD reported persisting cognitive or learning difficulties (all types combined) in contrast to $9 \%$ of the controls. The risk for the participants in the study group for experiencing subjective difficulties was more than 10-fold, particularly for learning problems, writing, as well as in dexterity/motor skills. They had had more remedial teaching as well (Table 7). 
Social situation and contacts. At the age of 30 , social wellbeing variables did not clearly differentiate between the study group and the controls especially after correction for multiple testing. The risk for a higher subjective need of social support, a lower satisfaction with social contacts, and not living with a spouse was elevated in the group with PRassociated ADHD, however.

Educational and occupational achievement. There were significant differences in the occupational outcomes between the groups. The relative risks for poor outcome in the group with PR-associated ADHD were three to eightfold. Twentytwo percent of the study group and 7\% of the controls had not completed any type of education after the obligatory school (second-level or third-level). Fewer participants in the study group had graduated from high school (19\% vs. $73 \%$ ) or university ( $8 \%$ vs. $34 \%$ ) compared with the controls. Fewer participants in the study group were gainfully employed on a whole-day basis ( $55 \%$ vs. $73 \%$ in the control group); others worked part-time or were unemployed. Nineteen percent of the participants with PR-associated ADHD and $2 \%$ of controls had been dismissed from work due to improper conduct and the number of past jobs was higher in the study group as well.

Psychiatric problems and health. The risk of a poorer subjective over-all health was fivefold in the study group as compared with that of controls. Prescription drug use (hypnotics or sedatives) was similar in the two groups. Only one participant with PR-associated ADHD was on prescribed psychostimulant regimen. General dissatisfaction with life, temper management problems, and anxiety were more commonly reported in the study group compared with controls. Two of the deceased had been treated for severe depression, and another two had received long-lasting psychotherapy. In those who returned the questionnaire, the reported frequency of depression was fairly high, but the differences in the psychiatric symptoms were not statistically significant when the number of comparisons was taken into account. The confidence intervals of the RR estimates for depression, depressive mood, and panic attacks nevertheless indicated a significantly elevated risk (Table 7).

Alcohol and illicit drugs. A significantly larger number of participants with PR-associated ADHD than controls admitted having driven intoxicated. Also the risks for alcohol and illicit drug use were elevated in the study group. Among the participants with PR-associated ADHD, 9 men (17\% of the 52 men in the study group) and 1 woman reported drinking daily or several times per week; in the controls 1 man and 1 woman reported similar drinking. In the study group, 19 men $(37 \%)$ and 6 women $(19 \%$ of the 32 women in the study group) used or had used cannabis in their lifetime. Seven men and 5 women also used or had used other illicit drugs, such as amphetamines, cocaine, heroin, lysergic acid diethylamide (LSD), or buprenorphine. In the control group, 9 men (22\% of the 41 men in the control group) and 3 women ( $6 \%$ of the 54 women in the control group) had used cannabis, and 2 (1 male, 1 female) reported having used other drugs.

\section{Discussion}

The aim of the study was to present the 30-year follow-up results of 122 male and female participants who all had ADHD associated with PRs, and to compare the long-term cognitive, social, occupational, and psychiatric outcome of this ADHD group with controls, similarly followed-up from childhood. Our results show a poorer long-term outcome in the ADHD associated with PR. The study group came from a consecutive cohort of 1,196 participants born in 1971 to 1974, and to the best of our knowledge, this is the most comprehensive study of a group of participants with ADHD diagnosed in childhood with regard to including both men and women and extending up to 30 years. Our ADHD group differs from previously published series in that it consists exclusively of participants with pre-existing PRs for neurodevelopmental disorders.

\section{The Diagnosis}

When this study began in 1971, the term Minimal Brain Dysfunction (MBD) was used (Clements, 1966; Hagberg, 1975). In our study, MBD was diagnosed if the child had impairments in at least three out of four areas of functioning: motor impairments, perceptual and learning difficulties, speech and language problems, or psychiatric/behavioral problems including hyperactivity. Thus, originally, MBD was a category of a variety of neurodevelopmental impairments not tied to a specific diagnosis. To confirm that the $D S M-I V$ criteria for an ADHD diagnosis were fulfilled, case records of all participants who had been diagnosed with MBD, as well as those with hyperactivity and inattention, were reviewed. Criteria symptoms were established in childhood allowing diagnosis of ADHD, although the subtypes of ADHD could not be determined reliably enough to be included in the statistical analysis. It is plausible that some cases with predominantly inattention symptoms were missed, but as the original focus of the study was not limited to hyperactivity, the number of undetected cases is probably low, and inconsequent for the conclusions.

In our cohort of newborns with PR factors, the frequency of ADHD was $14 \%$, which is considerably higher than the $5 \%$ reported for the general population (Polanczyk et al., 2007). Our prospective follow-up study therefore confirms observations of a higher incidence of ADHD in a population with PRs (Gustafsson \& Källén, 2011; Halmøy et al., 2012; Sagiv et al., 2013). The most common single observed risks 
were hyperbilirubinemia, low Apgar score, and low birth weight. Thirty percent had several concomitant risks which is a higher proportion of multiple risks than in the whole cohort (20\%). Also, maternal age and gestation weeks were different from those in the group. In a recent epidemiological record linkage study (Silva et al., 2013), young maternal age appeared to increase the risk of ADHD but in discordance to some previous reports, low Apgar scores or low birth weight did not. Jaundice was not reported in that study. Large linkage studies tend to estimate risks conservatively, but are less sensitive to bias that is involved in case control studies, for example caused by selection or chance. Although all participants in our cohort had PRs, simultaneous familial effects cannot be disregarded. Pre- and perinatal adverse events are to a certain degree chance occurrences, and may coincide with hereditary predisposition leading to combined etiology. Nevertheless, different symptomatology may be involved in different etiologies.

\section{ADHD in Adults}

Though ADHD was primarily considered to be a disease of childhood, it is now recognized that the symptoms continue into adulthood in a majority of participants with a prevalence of $2 \%$ to $5 \%$ in the population (Kooij et al., 2010). Two thirds of those diagnosed in childhood are found to have distressing symptoms in follow-up, although they do not fulfill all diagnostic ADHD criteria (Biederman et al., 2011; Faraone et al., 2006). In our study, 5 participants (1 combined, 4 inattention type) fulfilled the diagnostic criteria at age of 30 on the self-rated questionnaire of ADHD. This is a lower proportion than the suggested $15 \%$ to retain full diagnostic criteria in adulthood (Barkley et al., 2002; Biederman et al., 2000; Faraone et al., 2006). However, when the reported symptoms were all scored in terms of severity, the participants with PR-associated ADHD had significantly more problems than the controls. Using the summary score instead of symptom count is suggested to better capture the dimensional nature of the behavior (Barkley \& Murphy, 1998). In the recent DSM-5 (5th ed.; APA, 2013), this regression of symptoms has been accounted for by requiring fewer criteria symptoms for adults than for children.

Retrospective assessment suggested that 10 had been the combined type, 4 the inattention, and 9 the hyperactive/impulsive type in childhood. Compared with the current symptoms, this would imply improvement predominantly in the hyperactivity symptoms, as has been suggested previously (Biederman et al., 2000). However, retrospective evaluation of symptoms must be interpreted with high caution (Barkley et al., 2002; Mannuzza, Klein, Klein, Bessler, \& Shrout, 2002). It is noteworthy that of the 84 participants diagnosed by health professionals in childhood, only 23 (27\%) reported above threshold levels of symptoms retrospectively.
Our participants were drug-naive as psychostimulants had not been available in childhood and only one was on treatment in adulthood. Although medication reduces ADHD symptoms (Mannuzza et al., 2008; Surman, Hammerness, Pion, \& Faraone, 2013), psychostimulants were rarely used before the turn of the millennium in Finland, similar to many other parts of Europe (Kooij et al., 2010). Non-pharmacological interventions have been preferred instead. In our cohort the emphasis has been on the rehabilitative measures, and the study group was offered numerous types of rehabilitation and support, including parental and patient counseling, psychotherapy, physical rehabilitation, and occupational advising. Special school arrangements were also readily available and widely used. Our cohort therefore represents the natural course of unmedicated, but by no means untreated, ADHD.

\section{Educational and Occupational Outcome}

The children with PR-associated ADHD had multiple demonstrable behavioral, motor, perception, speech, language, and learning problems already at ages of five and nine. Thus, potential school problems could be predicted at age five as has been reported in more detail in our previous articles (Lindahl \& Michelsson, 1987; Michelsson \& Lindahl, 1987; Michelsson et al., 1981). Problems in learning skills were paralleled by the poorer performance in the cognitive and motor tests performed. The persistent difference in the cognitive scores between controls and the study group both at 5 and 9 years suggest no significant catch-up in the development of the participants with PR-associated ADHD. Reading, writing, and other difficulties in the study group also persisted in adulthood, and half reported subjective cognitive problems at the age of 30 . Comorbidity between ADHD and dyslexia has been found in several studies, and a shared multiple-deficit model is hypothesized (Willcutt et al., 2010).

The educational problems in the participants with PR-associated ADHD continued throughout their school years, as evidenced by behavioral problems, poor school grades, and repeating of classes. A threefold risk was found in the study group for a poorer educational outcome compared with the controls. Despite the offered remedial instruction, many participants with PR-associated ADHD preferred to start working rather than continue studies after graduating from school at the age of 16 . At age 30 , more than one out of five in the study group, but only $7 \%$ of the controls, still lacked an education beyond the obligatory school years.

The occupational outcome reflected a similar trend of underachievement. ADHD symptoms appeared to hamper adaptation to the work environment. One of five in the study group had been dismissed from their jobs, an eightfold increase in the risk compared with controls. Almost 
half of the participants with PR-associated ADHD (45\%) were in part-time jobs or unemployed. Studies from the United States have also found more unemployment and low-status jobs among the ADHD participants (Barkley, Fischer, Smallish, \& Fletcher, 2006; Biederman et al., 2012; Klein et al., 2012).

The socioeconomic status of the families of the children with PR-associated ADHD was lower to begin with, as assessed with the socioeconomic level of the father. A composite score reflecting psychosocial problems (divorces, relocations, family conflicts, domestic violence, mental problems, or physical illnesses in the family) was higher in the study group. The socioeconomic status did not explain the cognitive differences between the groups but poor environmental support may interfere with development and breed a lack of motivation to pursue studies or a career, and more problem behavior as a learned response to adversity. Careful clinical evaluations and a reliable ADHD diagnosis at an early age are important because they enable timely intervention and support for the family, thereby preventing secondary psychiatric and educational problems.

\section{Co-Morbid Psychiatric Disorders and Substance Abuse}

During childhood, $65 \%$ of participants with ADHD have one or more co-morbid condition and in adulthood, psychiatric comorbidities are more the rule (Kooij et al., 2010). In recent long-term follow-up studies of ADHD men, the results have been contradictory however, some observing a higher rate of lifetime anxiety as well as mood disorders (Biederman et al., 2012), and others observing no difference to controls (Klein et al., 2012). In our study, externalizing symptoms were more common in boys with PR-associated ADHD at the age of 16, but not in girls. In adulthood, the risk of anxiety was fivefold in the study group. The risk of depression was lower than for anxiety but as the risk of depressive mood was also elevated, the combined effect is noteworthy. Furthermore, the risk of suicide was apparent when both ideation and deaths by suicide are taken into account. The suicide risk in ADHD has been emphasized in recent reviews (Impey \& Heun, 2012; Nigg, 2013).

Alcohol and cannabis were the substances most frequently used in the study group, they are also the most frequently found in toxicological screenings of Finnish drivers suspected for driving intoxicated (Legrand et al., 2013). The relatively large number of drunk drivers among the group with PR-associated ADHD may suggest a more severe alcohol dependency in addition to impulse control problems. Excessive use of alcohol or drugs was also involved in several deaths within our cohort. The increase in substance abuse related to ADHD has been speculated to be caused by the positive effect on mood or the core symptoms. Problems with friends and relationships may increase the risk of substance abuse, and mediating effects have been reported also for personality disorders and conduct disorder (Klein et al., 2012). Substance use often associates with socially poorly adopted addiction prone subcultures, which makes differentiating social and neurochemical effects very demanding. In our study, alcohol and drug use was more prevalent in men than in women. In studies where only men are included, the estimated substance use may be exaggerated because of the gender effect. In spite of relatively low prevalence, our findings support the view that ADHD is a risk for substance abuse (Klein et al., 2012; Nigg, 2013).

\section{Strengths and Limitations}

Most of the studies on ADHD have presented findings of groups with unknown etiology. The presence or absence of PRs is difficult to establish retrospectively and estimates of the proportion of birth risks have not been reported in many studies. We consider the prospective follow-up of our cohort as the absolute strength of this study. It enables the analysis of etiologically relatively homogeneous group. The cohort also included both males and females, which improves the generalizability.

There was only one participant with ADHD in the control group, so it is not possible to compare the ADHD associated with PRs with an ADHD without a similar association. However, the low number of ADHD participants in the controls also emphasizes the role of perinatal events. Another limitation of our study is the descriptive nature of the outcome questionnaire, necessitating a large number of statistical comparisons. We used the Bonferroni correction to adjust the statistical significance for multiple testing. The Bonferroni method is generally regarded as very conservative, and true significant test results may have been rejected. Still, there were a number of clinically meaningful significant differences between ADHD participants and controls, supported by the RR statistics as well.

\section{Conclusion}

Adults with ADHD are said to often act without thinking, change jobs and relationships, and engage in risky and even criminal behavior (Kooij et al., 2010; Satterfield et al., 2007). They are more likely to be involved in driving and other accidents (Nigg, 2013), have depressive disorders, and are in increased risk of death by suicide (Impey \& Heun, 2012; Nigg, 2013). They also have a lower educational performance and work attainment (Barkley et al., 2006; Biederman et al., 2012; Klein et al., 2012). In this study on ADHD, participants originating from a cohort of newborns with significant PRs, all these problems were present. More importantly, the symptoms transformed from 
the childhood type disorder to an adult type of ADHD syndrome. The symptoms got milder with age, but were nevertheless remarkably constant.

At its worst, ADHD causes a high level of personal distress and considerable economic burden for both the family and the society if unidentified and untreated. On a group level, ADHD associated with PRs appears quite similar to the general description of ADHD. As seen in our study, the effects can still be seen in adulthood. The causes of ADHD are largely unknown but an association of PRs with ADHD symptoms would indicate that active maternal and perinatal care can provide a valuable means for prevention of ADHD.

\section{Declaration of Conflicting Interests}

The author(s) declared no potential conflicts of interest with respect to the research, authorship, and/or publication of this article.

\section{Funding}

The author(s) disclosed receipt of the following financial support for the research, authorship, and/or publication of this article: The first 20 years of the project were supported by the Academy of Finland, Signe and Ane Gyllenberg Foundation, Foundation of Pediatric Research, The Association for Life Insurance Companies, Traffic Insurer's Centre Finland, and Rinnekoti Foundation. No funding was obtained for the preparation of the current manuscript.

\section{References}

Achenbach, T. M., \& Eldebrock, C. (1987). Manual for the youth self-report and revised profile. Burlington: Department of Psychiatry, University of Vermont.

American Psychiatric Association. (1968). Diagnostic and statistical manual of mental disorders (2nd ed.). Washington, DC: Author.

American Psychiatric Association. (1994). Diagnostic and statistical manual of mental disorders (4th ed.). Washington, DC: Author.

American Psychiatric Association. (2013). Diagnostic and statistical manual of mental disorders (5th ed.). Arlington, VA: American Psychiatric Publishing.

Barkley, R. A., Fischer, M., Smallish, L., \& Fletcher, K. (2002). The persistence of attention-deficit/hyperactivity disorder into young adulthood as a function of reporting source and definition of disorder. Journal of Abnormal Psychology, 111, 279-289.

Barkley, R. A., Fischer, M., Smallish, L., \& Fletcher, K. (2006). Young adult outcome of hyperactive children: Adaptive functioning in major life activities. Journal of the American Academy of Child \& Adolescent Psychiatry, 45, 192-202.

Barkley, R. A., \& Murphy, K. R. (1998). Attention-deficit hyperactivity disorder: A clinical workbook (2nd ed.). New York, NY: Guilford Press.

Bax, M., \& Whitmore, K. (1983). Neurodevelopmental screening in the school-entrant medical examination. Lancet, 2, 368-370.

Biederman, J., Mick, E., \& Faraone, S. V. (2000). Age-dependent decline of symptoms of attention deficit hyperactivity disorder: Impact of remission definition and symptom type. American Journal of Psychiatry, 157, 816-818.

Biederman, J., Petty, C. R., Clarke, A., Lomedico, A., \& Faraone, S. V. (2011). Predictors of persistent ADHD: An 11-year follow-up study. Journal of Psychiatric Research, 45, 150-155.

Biederman, J., Petty, C., Woodworth, K., Lomedico, A., Hyder, L., \& Faraone, S. (2012). Adult outcome of attention-deficit/ hyperactivity disorder: A controlled 16-year follow-up study. The Journal of Clinical Psychiatry, 73, 941-950.

Clements, S. (1966). Minimal brain dysfunction in children. Terminology and identification (NINDM Monograph No. 3). Washington, DC: U.S. Department of Health, Education and Welfare

Dubowitz, L. M., Leibowitz, D., \& Goldberg, C. (1977). A clinical screening test for assessment of intellectual development in four-and five-year-old children. Developmental Medicine \& Child Neurology, 19, 776-782.

Faraone, S. V., Biederman, J., \& Mick, E. (2006). The age-dependent decline of attention deficit hyperactivity disorder: A meta-analysis of follow-up studies. Psychological Medicine, 36, 159-166.

Goodenough, F. L. (1926). Measurement of intelligence by drawings. Yonkers, NY: World Book Company.

Gustafsson, P., \& Källén, K. (2011). Perinatal, maternal, and fetal characteristics of children diagnosed with attention-deficithyperactivity disorder: Results from a population-based study utilizing the Swedish Medical Birth Register. Developmental Medicine \& Child Neurology, 53, 263-268.

Hagberg, B. (1975). Minimal brain dysfunction-What does it imply in child development and adaptation. Läkartidningen, 72, 296-300.

Halmøy, A., Klungsøyr, K., Skjærven, R., \& Haavik, J. (2012). Pre- and perinatal risk factors in adults with attention-deficit/ hyperactivity disorder. Biological Psychiatry, 71, 474-481.

Hokkanen, L., Launes, J., \& Michelsson, K. (2013). The perinatal adverse events and special trends in cognitive trajectory (PLASTICITY)-pre-protocol for a prospective longitudinal follow-up cohort study. F1000Research, 2, Article 50. doi:10.12688/f1000research.2-50.v1

Impey, M., \& Heun, R. (2012). Completed suicide, ideation and attempt in attention deficit hyperactivity disorder. Acta Psychiatrica Scandinavica, 125, 93-102.

Klein, R. G., Mannuzza, S., Olazagasti, M. A. R., Belsky, E. R., Hutchison, J. A., Lashua-Shriftman, E., \& Castellanos, F. X. (2012). Clinical and functional outcome of childhood ADHD 33 years later. Archives of General Psychiatry, 69, 1295-1303.

Kooij, S. J., Bejerot, S., Blackwell, A., Caci, H., Casas-Brugué, M., Carpentier, P. J., . . Asherson, P. (2010). European consensus statement on diagnosis and treatment of adult ADHD: The European Network Adult ADHD. BMC Psychiatry, 10, Article 67.

Kuusinen, L., \& Blåfield, L. (1974). Illinois Test of Psycholinguistic Abilities, Finnish edition (Report No. 234). Jyväskylä, Finland: Institute of Educational Research, University of Jyväskylä.

Lara, C., Fayyad, J., de Graaf, R., Kessler, R. C., AguilarGaxiola, S., Angermeyer, M., . . .Sampson, N. (2009). 
Childhood predictors of adult attention-deficit/hyperactivity disorder: Results from the World Health Organization World Mental Health Survey Initiative. Biological Psychiatry, 65, 46-54.

Legrand, S.-A., Isalberti, C., Linden, T. V., Bernhoft, I. M., Hels, T., Simonsen, K. W., . . .Verstraete, A. G. (2013). Alcohol and drugs in seriously injured drivers in six European countries. Drug Testing and Analysis, 5, 156-165.

Lindahl, E., \& Michelsson, K. (1987). Prognosis of neonatal "at risk" infants at early school-age: A comprehensive outcome score as a measure of impairment. Early Child Development and Care, 29, 23-41.

Mannuzza, S., Klein, R. G., Klein, D. F., Bessler, A., \& Shrout, P. (2002). Accuracy of adult recall of childhood attention deficit hyperactivity disorder. American Journal of Psychiatry, 159, 1882-1888.

Mannuzza, S., Klein, R., Truong, N., Moulton, J., Roizen, E., Howell, K., \& Castellanos, F. (2008). Age of methylphenidate treatment initiation in children with ADHD and later substance abuse: Prospective follow-up into adulthood. American Journal of Psychiatry, 165, 604-609.

Michelsson, K., \& Lindahl, E. (1987). School failure in a group of nine-year-old children who neonatally belonged to a high risk group. Early Child Development and Care, 29, 61-68.

Michelsson, K., Ylinen, A., \& Donner, M. (1981). Neurodevelopmental screening at five years of children who were at risk neonatally. Developmental Medicine \& Child Neurology, 23, 427-433.

Michelsson, K., Ylinen, A., Saarnivaara, A., \& Donner, M. (1978). Occurrence of risk factors in newborn infants. A study of 22,359 consecutive cases. Annals Clinical Research, 10, 334-336.

Nigg, J. T. (2006). What causes ADHD? Understanding what goes wrong and why. New York, NY: Guilford Press.

Nigg, J. T. (2013). Attention-deficit/hyperactivity disorder and adverse health outcomes. Clinical Psychology Review, 33, 215-228.

Polanczyk, G., de Lima, M., Horta, B., Biederman, J., \& Rohde, L. (2007). The worldwide prevalence of ADHD: A systematic review and metaregression analysis. American Journal of Psychiatry, 164, 942-948.

Ruoppila, I., Röman, K., \& Västi, M. (1968). Diagnostic Reading Tests for Grades II and III in the elementary school (Report No. 41). Jyväskylä, Finland: Institute of Educational Research, University of Jyväskylä.

Ruoppila, I., Röman, K., \& Västi, M. (1969). Diagnostic Writing Tests for Grades II and III in the elementary school (Report No. 50). Jyväskylä, Finland: Institute of Educational Research, University of Jyväskylä.

Sagiv, S. K., Epstein, J. N., Bellinger, D. C., \& Korrick, S. A. (2013). Pre-and postnatal risk factors for ADHD in a nonclinical pediatric population. Journal of Attention Disorders, 17, 47-57.

Satterfield, J. H., Faller, K. J., Crinella, F. M., Schell, A. M., Swanson, J. M., \& Homer, L. D. (2007). A 30-year prospective follow-up study of hyperactive boys with conduct problems: Adult criminality. Journal of the American Academy of Child \& Adolescent Psychiatry, 46, 601-610.
Silva, D., Colvin, L., Hagemann, E., \& Bower, C. (2014). Environmental risk factors by gender associated with attention-deficit/hyperactivity disorder. Pediatrics, 133(1), e14e22. doi:10.1542/peds.2013-1434

StatSoft, Inc. (2013). STATISTICA data analysis software system, version 12. Available from www.statsoft.com

Stott, D. H., Moyes, F. A., \& Henderson, S. A. (1972). A test of motor impairment. Guelph, Canada: Brook Educational Publishing.

Surman, C. B., Hammerness, P. G., Pion, K., \& Faraone, S. V. (2013). Do stimulants improve functioning in adults with ADHD? A review of the literature. European Neuropsychopharmacology, 23, 528-533.

Thapar, A., O’Donovan, M., \& Owen, M. J. (2005). The genetics of attention deficit hyperactivity disorder. Human Molecular Genetics, 14(Supp1. 2), R275-R282.

Wechsler, D. (1971). Wechsler Intelligence Scale for Children (WISC), Finnish edition. Helsinki, Finland: Psykologien Kustannus OY.

Willcutt, E. G., Betjemann, R. S., McGrath, L. M., Chhabildas, N. A., Olson, R. K., DeFries, J. C., \& Pennington, B. F. (2010). Etiology and neuropsychology of comorbidity between RD and ADHD: The case for multiple-deficit models. Cortex, 46, 1345-1361.

\section{Author Biographies}

Timo Tervo is a professor of Traffic Medicine of Helsinki University. He was earlier a professor of Applied Clinical Ophthalmology in Helsinki University Eye Hospital. His research has been focused on corneal diseases, infections and inflammations, refractive surgery, ocular nerves and pain - and during the last 15 years traffic medicine and vehicle safety technology. He is also an accident investigator besides his clinical work as an ophthalmologist.

Katarina Michelsson is retired from Department of Pediatrics, Helsinki University Hospital, Finland. She has held the position of chief administrative doctor and was appointed as associate professor of Pediatrics. Her research has included studies on infant crying, and she initiated the longitudinal follow-up of birth risk neonates, a project now re-named "Plasticity." Based on this cohort, she has published extensively on minimal brain dysfunction, and later ADHD. She has been the pioneering proponent for better care of ADHD and has advanced public awareness of ADHD.

Jyrki Launes is a clinical neurologist and assistant professor of neurology currently affiliated to the "Plasticity" follow-up cohort study at the Institute of Behavioural Sciences, University of Helsinki, Finland. His research has been focused on structural and molecular brain imaging and their clinical applications with special reference to CNS infections and memory.

Laura Hokkanen is a professor of Clinical Neuropsychology at the Institute of Behavioural Sciences, University of Helsinki, Finland. Her research has been focused on infectious as well as degenerative memory disorders, and more recently on the shared and non-shared cognitive features of adult ADHD and dyslexia. She is currently studying the long-term adult outcome of perinatal factors considered risk for early cognitive development. 